\title{
RESEARCH
}

\section{TNM 8th edition in thyroid cancer staging: is there an improvement in predicting recurrence?}

\author{
Olimpia Alice Manzardo1,*, Miriam Cellini1,2,*, Rita Indirli33,4, Alessia Dolci3,4, Paolo Colombo1, Flaminia Carrone1, \\ Elisabetta Lavezzi', Giovanna Mantovani3,4, Gherardo Mazziotti1,5, Maura Arosio ${ }^{3,4}$ and \\ Andrea Gerardo Antonio Lania1,5 \\ 1Endocrinology, Diabetology and Andrology Unit, Humanitas Clinical and Research Center, IRCCS, Rozzano, Milan, Italy \\ 2Department of Medical-Surgical Sciences and Biotechnologies, 'Sapienza' University of Rome, Latina, Italy \\ ${ }^{3}$ Department of Clinical Sciences and Community Health, University of Milan, Milan, Italy \\ 4Endocrinology Unit, Fondazione IRCCS Ca' Granda Ospedale Maggiore Policlinico, Milan, Italy \\ ${ }^{5}$ Department of Biomedical Sciences, Humanitas University, Rozzano, Milan, Italy
}

Correspondence should be addressed to G Mazziotti: gherardo.mazziotti@hunimed.eu

*(O A Manzardo and M Cellini contributed equally to this work)

\begin{abstract}
TNM $8^{\text {th }}$ edition introduces changes in the staging of patients with differentiated thyroid carcinoma (DTC). This study aims at assessing the value of TNM $8^{\text {th }}$ edition in predicting response to therapy and structural recurrence of DTC. Four hundred and eighty DTC patients were retrospectively evaluated by $7^{\text {th }}$ and $8^{\text {th }}$ editions of TNM staging system in relationship with risk stratification, response to therapy and recurrence of disease as defined by 2015 ATA guidelines. As compared to the $7^{\text {th }}$ edition, TNM $8^{\text {th }}$ led to downstage 136 patients $(28.3 \%)$, with $97.5 \%$ of patients falling into lower stages (I-II) and only $2.5 \%$ remaining in higher stages $(\mathrm{III}-\mathrm{IV})(P<0.001)$. Patients who were downstaged in stages I-II by TNM $8^{\text {th }}$ were classified more frequently at intermediate-high risk $(P<0.001)$, had more frequently structural incomplete response to therapy $(P=0.009)$ and had higher risk of structural recurrence $(P=0.002)$ as compared to patients who were in the same TNM stages but were not downstaged. Specifically, the risk of structural recurrence was significantly higher in patients in whom the downstaging was induced by changes in tumour classification (hazard ratio (HR) $6.18,95 \% \mathrm{Cl} 2.20-17.40 ; P=0.001$ ) but not in those who were downstaged for the increase in age cut-off ( $\mathrm{HR} 2.80,95 \% \mathrm{Cl}$ 0.86-9.19; $P=0.09$ ). In conclusion, TNM $8^{\text {th }}$ edition did not show reliability in predicting aggressiveness of DTC. In fact, the downstaging of DTC patients especially when performed due to changes in tumour classification may overlook patients predisposed to structural recurrence, potentially causing uncertainty in the therapeutic decision-making at the time of disease's diagnosis.
\end{abstract}

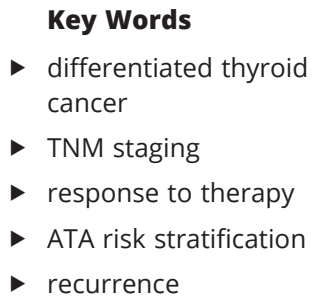

Endocrine-Related Cancer (2020) 27, 325-336

\section{Introduction}

Differentiated thyroid carcinoma (DTC) represents about $90 \%$ of all thyroid cancers and is the most frequent endocrine tumour. Although incidence of DTC has been rising steadily in most areas of the world over the last few decades, mortality has changed minimally, mainly as a result of increased use of diagnostic c) 2020 Society for Endocrinology Published by Bioscientifica Ltd. Printed in Great Britain 
imaging and surveillance (Haugen et al. 2016, Amin et al. 2017, Schmidbauer et al. 2017, Pacini et al. 2018). Facing the important increase in incidence and stable mortality of thyroid carcinoma, the $8^{\text {th }}$ edition of the AJCC (American Joint Commission on Cancer)/ TNM (Tumor Node Metastasis) manual, released in 2017, brings about important changes in the staging of patients with DTC. The main changes include an increase of the age threshold from 45 to 55 years to define patients with high risk of thyroid cancer-related death and a decrease in the negative prognostic value given to histopathological findings such as lymph node metastases and microscopic extrathyroidal extension (ETE). In fact, microscopic ETE was removed from the definition of T3 disease. These changes were proposed in order to increase the specificity and positive predictive value of TNM staging system in identifying patients with poor prognosis and low disease-specific and overall survival (Amin et al. 2017).

TNM staging is certainly useful in predicting disease mortality (Kim et al. 2017a,c, 2018b, Tam et al. 2018) and it is recommended for all DTC patients (Haugen et al. 2016). Since an objective of the staging systems is to guide the clinician in the planning of treatment (Brierley et al. 2017), one could argue that this planning cannot be solely based on the disease-related mortality that is relatively low in patients with DTC. However, the risk of recurrence is not negligible in DTC and many patients require repetitive treatments over the years, with a high clinical burden (Schmidbauer et al. 2017). Therefore, since disease-free survival has become a widely accepted endpoint for development of drugs and treatment procedures (Fiteni et al. 2014), it is reasonable to hypothesize that it may be valid also for the staging system like TNM. The current American Thyroid Association (ATA) guidelines proposed a risk stratification system and response to therapy categories with the intent to identify more aggressive tumours and to predict recurrence of disease in DTC patients (Haugen et al. 2016). Although the TNM is one of the major players for the classification of the ATA risk level, it is still unclear whether the new edition of TNM staging system may provide some information to predict the aggressiveness of DTC in addition to mortality (Lamartina et al. 2018, Nam et al. 2018, Nava et al. 2019).

Therefore, in this retrospective-longitudinal study we aimed at assessing a new possible role to the $8^{\text {th }}$ edition of TNM staging system in predicting the response to therapy and recurrence of DTC.

\section{Materials and methods}

\section{Study group}

This study was carried out in two tertiary care Endocrine Units of Milan, Italy (Humanitas Research Center, IRCCS and IRCCS $\mathrm{Ca}^{\prime}$ Granda Ospedale Maggiore Policlinico). This multicenter retrospective observational study was approved by Humanitas Clinical and Research Center and IRCCS Ca' Granda Ospedale Maggiore Policlinico Ethical Committees, a written consent was not needed due to the observational and retrospective nature of the study.

The inclusion criteria were: (1) age $>18$ years, (2) histological diagnosis of DTC, (3) $\geq 6$ months-follow-up post-thyroid surgery, and (4) availability of clinical data used by the TNM staging systems (Edge et al. 2010, Amin et al. 2017) and ATA classification of DTC (Haugen et al. 2016). Exclusion criteria were: (1) presence of concomitant non-thyroid cancers and (2) foci of poorly differentiated carcinoma at histology of thyroid specimens. From the internal databases, we retrospectively evaluated 503 patients with a diagnosis of DTC, who underwent thyroid surgery in the aforementioned Institutions from March 1980 to June 2018. Medical charts were reviewed and the following clinical variables were collected for each patient: sex, age at diagnosis, type of surgery, histopathologic findings (including histotype, tumour size, presence of angioinvasion, and extrathyroidal extension), duration of follow-up, and TNM staging ( $7^{\text {th }}$ and $8^{\text {th }}$ edition). The ATA risk stratification (low, intermediate, and high) and ATA response to initial therapy categories (excellent, indeterminate, biochemical incomplete, and structural incomplete) were retrospectively evaluated on the basis of available data.

Patients were followed up according to current guidelines at the time of clinical evaluations and then retrospectively stratified according to the latest ATA guidelines (Haugen et al. 2016). Biochemical evaluation of basal thyroglobulin ( $\mathrm{Tg}$ ), stimulated $\mathrm{Tg}$ postoperatively, and anti-Tg antibodies associated with neck ultrasound were carried out in all patients during the follow-up. In specific cases, other radiological tests (CT, PET, magnetic resonance, and bone scan) were performed.

Out of the 503 patients treated for DTC at our institutions, 480 DTC patients met the inclusion criteria and were included in the study. The median follow-up was 59 months (range 6-441). The clinical and pathological characteristics of the sample are summarized in Table 1 . All patients were staged by the $7^{\text {th }}$ and $8^{\text {th }}$ edition of the TNM systems and results were compared each other
C) 2020 Society for Endocrinology Published by Bioscientifica Ltd. Printed in Great Britain 
Table 1 Clinical and histopathological characteristics of the study group.

\begin{tabular}{|c|c|c|}
\hline & Characteristics & Patients $(\mathrm{n}) /$ value \\
\hline \multirow[t]{5}{*}{ Patient characteristics } & Total & 480 \\
\hline & Female (\%) & $364(75.8)$ \\
\hline & Male (\%) & $116(24.2)$ \\
\hline & Mean age at diagnosis (S.D.) & $49( \pm 14)$ \\
\hline & Median follow up, months (range) & $59(6-441)$ \\
\hline \multirow[t]{10}{*}{ Histopathological findings } & Histology: & \\
\hline & Papillary (\%) & $438(91.2)$ \\
\hline & Follicular (\%) & $33(6.9)$ \\
\hline & Papillary and follicular (\%) & $9(1.9)$ \\
\hline & Median tumour diameter, mm (range) & $12(1-100)$ \\
\hline & Angioinvasion (\%) & $83(17.3)$ \\
\hline & Minimal extrathyroid extension (\%) & $78(16.3)$ \\
\hline & Gross extrathyroid extension (\%) & $16(3.3)$ \\
\hline & Lymph node metastases, N1 (\%) & $115(24)$ \\
\hline & Distant metastases, M1 (\%) & $5(1)$ \\
\hline \multirow[t]{11}{*}{ Treatment } & Surgical: & \\
\hline & Total/near-total thyroidectomy (\%) & $454(94.6)$ \\
\hline & Lobectomy (\%) & $26(5.4)$ \\
\hline & Neck dissection (\%) & $182(38)$ \\
\hline & Post-surgical: & \\
\hline & Radioiodine ablation (\%) & $322(67.1)$ \\
\hline & Median first dose, MBq (range) & $2960(1110-7740)$ \\
\hline & Repeat radioiodine ablation (\%) & $40(12.4)$ \\
\hline & Median cumulative dose, MBq (range) & $2960(1110-28,090)$ \\
\hline & Reoperation (\%) & $29(6)$ \\
\hline & Second line treatments (\%) & $10(2.1)$ \\
\hline \multirow[t]{2}{*}{ Follow-up } & Relapses (\%) & $41(9.2)$ \\
\hline & Deaths from thyroid cancer (\%) & $0(0)$ \\
\hline \multirow[t]{3}{*}{ Initial ATA risk stratification } & Low risk (\%) & $251(52.3)$ \\
\hline & Intermediate risk (\%) & $196(40.8)$ \\
\hline & High risk (\%) & $33(6.9)$ \\
\hline \multirow[t]{4}{*}{ ATA response to therapy } & Excellent response (\%) & $444(92.5)$ \\
\hline & Biochemical incomplete response (\%) & $8(1.7)$ \\
\hline & Structural incomplete response (\%) & $13(2.7)$ \\
\hline & Indeterminate response (\%) & $15(3.1)$ \\
\hline
\end{tabular}

and were related with the risk stratification, response to therapy, and recurrence of disease as defined by the 2015 ATA guidelines.

The primary end-point was to assess the ability of $8^{\text {th }}$ edition of TNM staging system in predicting structural recurrences in patients with DTC. The secondary endpoints were: (1) to assess the correlation between TNM $8^{\text {th }}$ edition and response to therapy, (2) to assess the correlation between TNM $8^{\text {th }}$ edition and ATA risk stratification, and (3) to compare the $7^{\text {th }}$ and $8^{\text {th }}$ editions of TNM.

\section{TNM staging systems}

Each DTC patient was staged according to the $7^{\text {th }}$ and $8^{\text {th }}$ editions of AJCC/TNM as stage I, II, III, or IV (Edge et al. 2010, Amin et al. 2017). The criteria to define the stage in TNM $7^{\text {th }}$ and TNM $8^{\text {th }}$ edition are summarized in Table 2 (Lamartina et al. 2018).

\section{ATA initial risk stratification and response to therapy categories}

Based on clinical, histological, and molecular characteristics of DTC, each patient was classified according to the Initial Risk Stratification System proposed by 2015 ATA guidelines into three risk categories: low, intermediate, and high (Haugen et al. 2016).

The response to initial therapy in patients treated with total thyroidectomy and radioiodine remnant ablation was classified and continually assessed during follow-up, according to ATA guidelines (Haugen et al. 2016) as follows: (1) excellent response without evidence of clinical, biochemical (suppressed $\mathrm{Tg}<0.2 \mathrm{ng} / \mathrm{mL}$ or stimulated $\mathrm{Tg}<1 \mathrm{ng} / \mathrm{mL}$, negative anti-Tg antibodies), or structural disease; (2) indeterminate response with nonspecific biochemical (suppressed Tg detectable, but $<1 \mathrm{ng} / \mathrm{mL}$ or stimulated Tg detectable, but $<10 \mathrm{ng} / \mathrm{mL}$, declining or stable anti-Tg antibodies) or structural
(C) 2020 Society for Endocrinology Published by Bioscientifica Ltd. Printed in Great Britain 
Table 2 Comparison of the $7^{\text {th }}$ and $8^{\text {th }}$ editions of TNM staging system.

\begin{tabular}{|c|c|c|c|}
\hline \multicolumn{3}{|c|}{$7^{\text {th }}$ edition Age $<45$ years } & \multirow{3}{*}{$\begin{array}{l}\text { M0 } \\
\text { M1 }\end{array}$} \\
\hline I & Any $T$ & Any $\mathbf{N}$ & \\
\hline II & Any $\mathrm{T}$ & Any N & \\
\hline \multicolumn{3}{|c|}{$7^{\text {th }}$ edition Age $\geq 45$ years } & \\
\hline I & $\begin{array}{l}\text { Tumour } \leq 2 \mathrm{~cm} \text { limited to the } \\
\text { thyroid (T1) }\end{array}$ & Nx/NO & MO \\
\hline II & $\begin{array}{l}\text { Tumour } \leq 4 \mathrm{~cm} \text { limited to the } \\
\text { thyroid (T2) }\end{array}$ & Nx/NO & MO \\
\hline
\end{tabular}

III

Any T with lymph node metastases of central compartment (N1a) or with minimal ETE (T3) with or without lymph node metastases of the central compartment

IVa

Any T with lymph node metastases of lateral compartment (N1b) or with gross ETE invading sub-cutaneous soft tissues, larynx, trachea, oesophagus, or RLN (T4a) with or without lymph node metastases

IVb Any T with gross ETE invading
prevertebral fascia or encasing
the carotid artery or mediastina vessels (T4b)

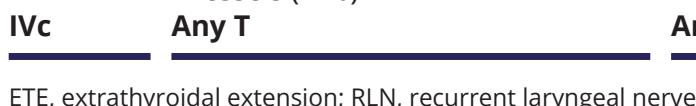

findings; (3) biochemical incomplete response (suppressed $\mathrm{Tg} \geq 1 \mathrm{ng} / \mathrm{mL}$ or stimulated $\mathrm{Tg} \geq 10 \mathrm{ng} / \mathrm{mL}$ or abnormal $\mathrm{Tg}$ or rising anti-Tg antibodies) in the absence of localizable disease; and (4) structural incomplete response with evidence of persistent or new loco-regional or distant metastases. The response to initial therapy in patients treated with total thyroidectomy without radioiodine remnant ablation was defined as follows: (1) excellent response without evidence of clinical, biochemical (suppressed $\mathrm{Tg}<0.2 \mathrm{ng} / \mathrm{mL}$ or stimulated $\mathrm{Tg}<2 \mathrm{ng} / \mathrm{mL}$, negative anti-Tg antibodies), or structural disease; (2) indeterminate response with nonspecific biochemical (suppressed Tg $0.2-5 \mathrm{ng} / \mathrm{mL}$ or stimulated Tg $2-10 \mathrm{ng} / \mathrm{mL}$, declining or stable anti-Tg antibodies) or structural findings; (3) biochemical incomplete response (suppressed $\mathrm{Tg}>5 \mathrm{ng} / \mathrm{mL}$ or stimulated $\mathrm{Tg}>10 \mathrm{ng} / \mathrm{mL}$ or increasing $\mathrm{Tg}$ values with stable TSH levels or rising anti-Tg antibodies) in the absence of localizable disease; and (4) structural incomplete response with evidence of persistent or new loco-regional or distant metastases (Momesso \& Tuttle 2014, Momesso et al. 2016). The response to initial therapy in patients treated with lobectomy alone was classified as follows: (1) excellent response without evidence of clinical, biochemical (suppressed $\mathrm{Tg}<30 \mathrm{ng} / \mathrm{mL}$, negative anti-Tg antibodies), or structural disease; (2) indeterminate response with declining or stable anti-Tg

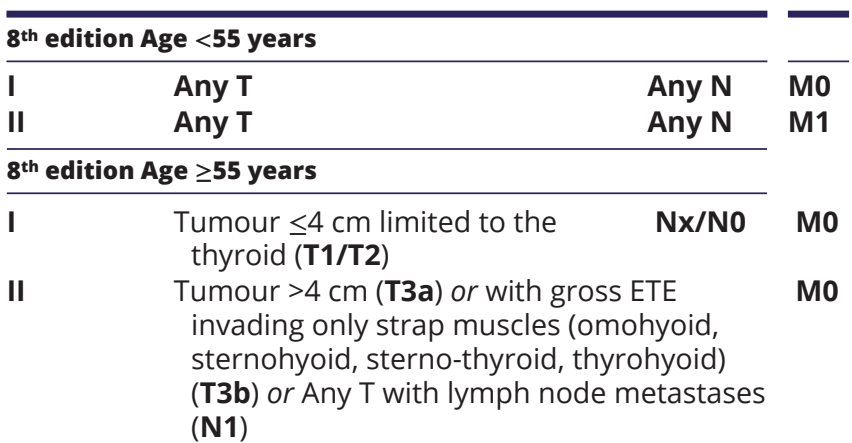

Any T with gross ETE invading
subcuta-neous soft tissues,

Any N Mo

larynx, trachea, oesophagus or RLN (T4a)

IVa

Any T with gross ETE invading prevertebral fascia or encasing the carotid artery or mediastinal vessels (T4b)

Any N Mo

Any $T$

Any N https://erc bioscientifica.com

https://doi.org/10.1530/ERC-19-0412
C) 2020 Society for Endocrinology Published by Bioscientifica Ltd. Printed in Great Britain antibodies) without structural and functional disease or nonspecific structural findings in imaging studies; (3) biochemical incomplete response with suppressed $\mathrm{Tg}>30 \mathrm{ng} / \mathrm{mL}$, increasing Tg values with stable TSH level, or rising anti-Tg antibodies in the absence of localizable disease; and (4) structural incomplete response with evidence of persistent or new loco-regional or distant metastases (Momesso \& Tuttle 2014, Momesso et al. 2016).

For the assessment of response to therapy, patients were firstly evaluated 6 months after the initial therapy and then monitored every 6-12 months during the follow-up. Patients with incomplete or indeterminate disease at the first clinical evaluation were monitored until an excellent response was achieved or a second treatment was performed. Patients who had initial incomplete or indeterminate response to therapy and did not achieve excellent response, as well as those undergoing a second treatment of DTC, were classified as having persistent disease.

\section{Definition of recurrences}

Only patients with excellent response (Haugen et al. 2016) were eligible for evaluation of disease recurrence, which was defined as a new appearance of disease after more than 12 months of follow-up. Biochemical recurrence was diagnosed in patients with elevated $\mathrm{Tg}$ (suppressed or stimulated) and/or appearance or progressive increase 
of anti-Tg antibodies levels without structural findings, in accordance to the surgical and radioablative treatment received, as previously mentioned. Structural recurrences were defined by the following conditions: (1) presence of suspicious lymph nodes in the central or lateral neck compartments or suspicious tissue in the thyroid bed confirmed by fine-needle aspiration biopsy and (2) positive findings on radioactive iodine (RAI) scans, 18F-FDG-PET scans, or other imaging suspicious for metastatic disease with or without histological/cytological confirmation. In order to avoid potential pitfalls in the retrospective analysis of data supporting the definition of biochemical recurrences, structural recurrences were considered as first end-point of the study.

\section{Statistical analysis}

Data were described as number and percentage if categorical or mean and if continuous. An independent $t$-test was used to evaluate the differences between the means of groups. Comparisons between groups were made with Chi-Square test or Fisher's Exact test, as appropriate. When these comparisons were multiple, Bonferroni's correction was performed. Logistic regression analysis was performed, and the odds ratios (OR) along with $95 \%$ confidence intervals (95\% CI) were calculated, to evaluate the determinants of excellent response to therapy. Disease-free survival time was calculated from first RAI therapy (or date of surgery for patients who did not undergo RAI therapy) to first recurrence date, defined as the presence of structural disease, or last visit date for not recurrent patients. The determinants of disease-free survival were sought using the Cox regression analysis with calculation of the hazard ratios (HR) and 95\% CI.
A $P$ value of $<0.05$ was considered as significant. All analyses were made with Stata13 and INSTAT GraphPad Prism 5.0 software.

\section{Results}

\section{TNM staging}

According to the $7^{\text {th }}$ edition of TNM, the distribution of patients was as follows: $70.0 \%, 7.3 \%, 14.4 \%$, and $8.3 \%$ in stage I, stage II, stage III, and stage IV, respectively. By restaging the same patients according to the $8^{\text {th }}$ edition of TNM, the distribution changed to $89.2 \%, 8.3 \%, 0.8 \%$, and $1.7 \%$ for stages I, II, III and IV, respectively $(P<0.001$ vs TNM $7^{\text {th }}$ ), thus with downstaging of 136 patients (28.3\%) (Fig. 1). Specifically, using the TNM $8^{\text {th }}$ edition, 92 patients were downstaged to stage I ( 35 from stage II, 42 from stage III, and 15 from stage IV), 40 to stage II (27 from stage III and 13 from stage IV), and 4 patients were downstaged from stage IV to stage III. In 66 patients $(48.5 \%)$, the downstaging was caused by the increase in the age cutoff (63 cases in stage I and 3 in stage II), whereas the remaining 70 patients $(51.5 \%)$ were downstaged due to changes in criteria of tumour classification (29 cases in stage I, 37 in stage II, and 4 in stage III).

\section{ATA risk stratification and TNM staging}

In the whole group, according to the ATA risk stratification, 251 patients (52.3\%) fell into the low-risk category, 196 (40.8\%) into the intermediate category, and 33 patients (6.9\%) into the high-risk category. Applying the TNM $7^{\text {th }}$ staging system, the prevalence of intermediate-high ATA risk was significantly higher in stages III and IV as

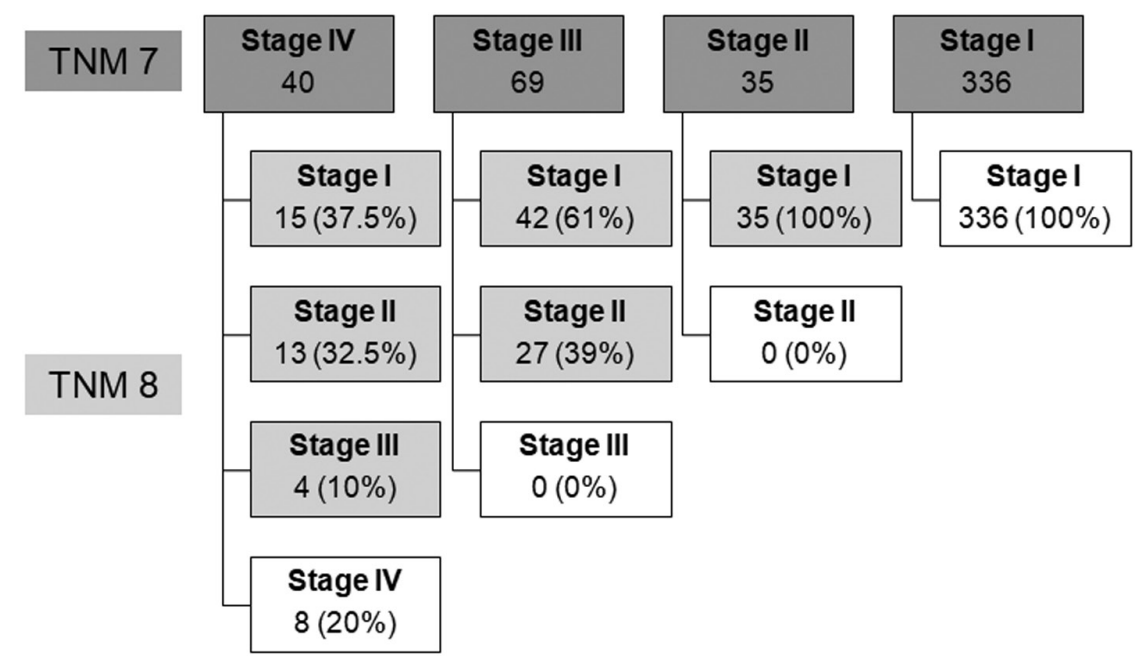

Figure 1

Redistribution of patients among stages, when switching from TNM $7^{\text {th }}$ to TNM $8^{\text {th }}$. The gray boxes included the downstaged patients. 
compared to stages I and II $(P<0.001)$, without significant differences between stages I and II and between stages III and IV (Fig. 2A). Applying the TNM $8^{\text {th }}$ staging system, the prevalence of intermediate-high ATA risk was higher in stages II, III, and IV as compared to the stage I (Fig. 2B).

Restricting the analysis to the patients who were classified in the lowest stages (i.e. stages I-II) by TNM $8^{\text {th }}$ edition, the prevalence of intermediate-high risk ATA category was significantly higher in patients who were downstaged as compared to those who were not downstaged $(80.3 \%$ vs $33.1 \% ; P<0.001)$. The prevalence of intermediate-high ATA risk category was not significantly different between downstaged patients for increase in the age cut-off and those in whom the downstaging was caused by changes in criteria of tumour classification (77.3 vs $83.3 \% ; P=0.38$ ).

\section{Response to therapy and TNM staging}

Six months after the initial therapy, according to the ATA's criteria of response to therapy, 348 patients (72.5\%) showed an excellent response, 59 patients (12.3\%) an
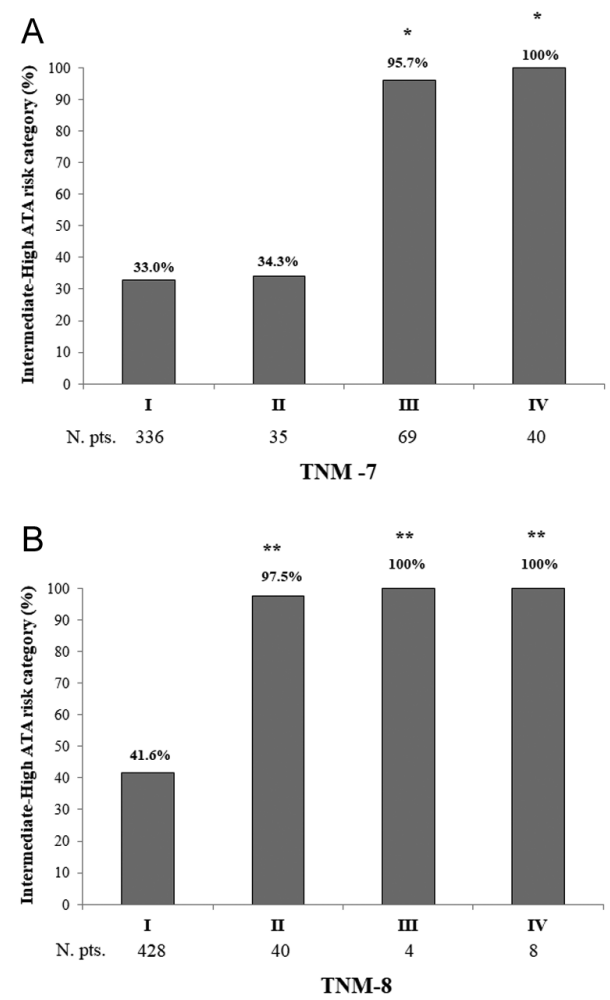

Figure 2

Distribution of intermediate-high ATA risk categories in different stages by TNM $7^{\text {th }}(A)$ and TNM $8^{\text {th }}$ (B) systems. The number of patients within each group was specified underneath the bars. ${ }^{*} P<0.001$ vs TNM 7 th stages I and II; $* * P<0.001$ vs TNM $8^{\text {th }}$ stage I.

(c) 2020 Society for Endocrinology Published by Bioscientifica Ltd. Printed in Great Britain indeterminate response, 45 patients $(9.4 \%)$ a biochemical incomplete response, and 28 patients $(5.8 \%)$ had a structural incomplete response. During the follow-up, other 96 patients achieved excellent response (overall 444 cases, $92.5 \%$ ), whereas 36 patients had persistent disease (8 cases with biochemical incomplete response, 13 cases with structural incomplete response, and 15 cases with indeterminate response). The percentage of excellent biochemical response was significantly lower in patients classified in the intermediate-high ATA risk category as compared to those in the low-risk ATA category $(89.5 \%$ vs $95.2 \% ; P=0.02$ ). Applying the TNM $7^{\text {th }}$ staging system, the excellent response was less frequent in patients with stage IV as compared to the other stages, without significant differences among stages I, II, and III (Fig. 3A). Applying the TNM $8^{\text {th }}$ staging system, the rate of excellent response was significantly higher in stage I as compared to stage IV, without significant differences among stages II and III (Fig. 3B). In the multivariate logistic regression analyses, excellent response maintained the significant association with TNM $8^{\text {th }}$, but not with TNM $7^{\text {th }}$ and ATA stratification risk (Table 3). Similar results were obtained when the
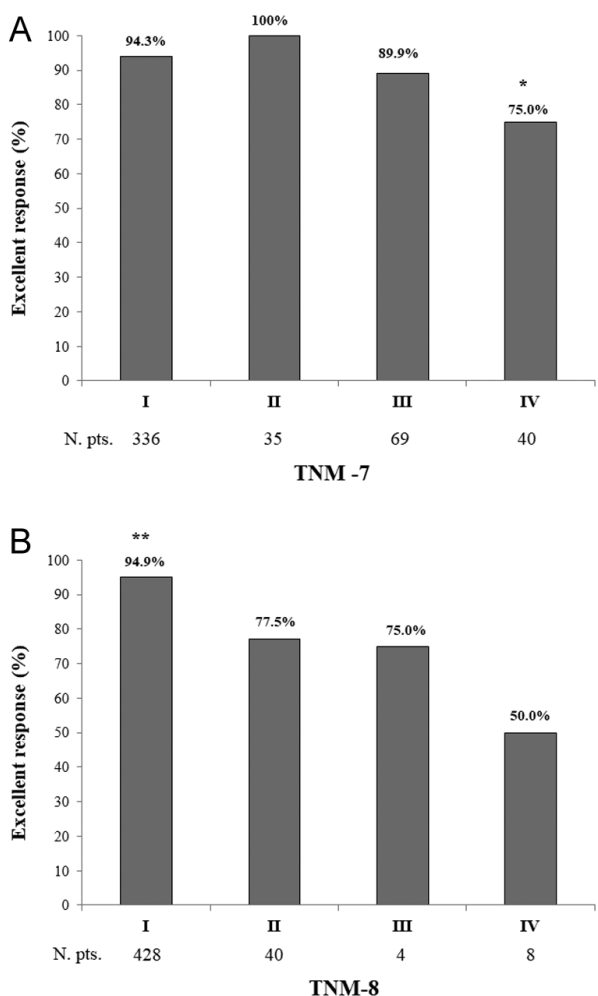

Figure 3

Distribution of excellent response to therapy in different stages by TNM $7^{\text {th }}(A)$ and TNM $8^{\text {th }}(B)$ systems. The number of patients within each group was specified underneath the bars. ${ }^{*} P<0.001$ vs TNM $7^{\text {th }}$ stages I, II and III; $* * P<0.001$ vs TNM $8^{\text {th }}$ stage IV. 
Table 3 Results of univariate and multivariate logistic regression analyses evaluating the determinants of excellent response to therapy.

\begin{tabular}{|c|c|c|c|}
\hline & \multicolumn{3}{|c|}{ Whole population (480 cases) } \\
\hline & \multirow[t]{2}{*}{ Univariate analysis OR $(95 \% \mathrm{Cl})$} & \multicolumn{2}{|c|}{ Multivariate analysis OR $(95 \% \mathrm{Cl})$} \\
\hline & & Model\#1 & Model\#2 \\
\hline Age & $0.98(0.96-1.01 ; P=0.12)$ & - & - \\
\hline Sex (males vs females) & $1.87(0.91-3.82 ; P=0.09)$ & - & - \\
\hline $\begin{array}{l}\text { ATA risk stratification (intermediate-high } \\
\text { risk vs low risk) }\end{array}$ & $0.42(0.25-0.69 ; P=0.01)$ & $0.60(0.31-1.16 ; P=0.13)$ & $0.77(0.39-1.48 ; P=0.43)$ \\
\hline TNM-7th staging system & $0.59(0.45-0.79 ; P<0.001)$ & $0.71(0.31-1.16 ; P=0.07)$ & - \\
\hline \multirow[t]{4}{*}{ TNM-8th staging system } & $0.34(0.22-0.52 ; P<0.001)$ & - & $0.39(0.23-0.69 ; P=0.001)$ \\
\hline & \multicolumn{3}{|c|}{ Patients in stages I-II by TNM-8th (468 cases) } \\
\hline & Univariate analysis OR $(95 \% \mathrm{Cl})$ & \multicolumn{2}{|c|}{ Multivariate analysis OR $(95 \% \mathrm{Cl})$} \\
\hline & & Model\#1 & Model\#2 \\
\hline Age & $0.99(0.97-1.012 ; P=0.58)$ & - & - \\
\hline Sex (males vs females) & $1.58(0.72-3.47 ; P=0.25)$ & - & - \\
\hline $\begin{array}{l}\text { ATA risk stratification (intermediate-high } \\
\text { risk vs low risk) }\end{array}$ & $0.56(0.31-0.99 ; P=0.05)$ & $0.75(0.36-1.55 ; P=0.44)$ & $0.79(0.40-1.55 ; P=0.48)$ \\
\hline TNM-7th (III-IV vs I-II stages) & $0.38(0.18-0.82 ; P=0.01)$ & $0.47(0.19-1.20 ; P=0.11)$ & - \\
\hline TNM- $8^{\text {th }}$ (II vs I stage) & $0.19(0.08-0.44 ; P<0.001)$ & - & $0.22(0.08-0.57 ; P=0.002)$ \\
\hline
\end{tabular}

Model\#1: TNM-7 ${ }^{\text {th }}$ and ATA risk stratification; Model\#2: TNM- $8^{\text {th }}$ and ATA risk stratification

patients were classified in a two-tiered staging system (i.e. TNM $7^{\text {th }} / 8^{\text {th }}$ stages I-II vs TNM $7^{\text {th }} / 8^{\text {th }}$ stages III-IV) and the regression analyses were restricted in the subgroup of patients (468 cases) with the stages I-II according to TNM $8^{\text {th }}$ (Table 3). The multivariate logistic analyses performed in this subgroup of patients showed that only TNM $8^{\text {th }}$ (i.e. stages I vs stage II) was associated with excellent response to therapy, whereas neither TNM $7^{\text {th }}$ (stage I-II vs II-IV) nor the ATA risk stratification (intermediate-high risk vs low risk) maintained the significant associations found in the univariate analysis. Moreover, in patients with stages I-II defined by TNM $8^{\text {th }}$ edition, the prevalence of persistent disease with biochemical and structural incomplete response was significantly higher in downstaged cases as compared to those who were not downstaged $(6.8 \%$ vs $2.1 \% ; P=0.009)$. The percentage of persistent disease with incomplete response (either biochemical or structural) was comparable between downstaged patients for increase in the age cut-off and those in whom the downstaging was caused by changes in criteria of tumour classification (7.6\% vs $6.0 \% ; P=0.92)$.

\section{Disease recurrence and TNM staging}

The analysis of recurrence was performed in 444 patients who had achieved excellent response after treatment of DTC. During the follow-up, 41 patients (9.2\%) experienced a recurrence of DTC: biochemical recurrence in 19 patients and structural recurrence in 22 patients (lymph nodes alone in 18 cases and distant metastases in 4 cases).
In the univariate Cox analysis, structural recurrences were predicted by ATA risk stratification and both TNM staging systems (Table 4). In the multivariate Cox regression analyses, risk of structural recurrence was predicted only ATA risk stratification, whereas the associations with TNM staging systems were lost (Table 4). However, when the patients were classified in a two-tiered staging system (i.e. TNM $7^{\text {th }} / 8^{\text {th }}$ stages I-II vs TNM $7^{\text {th }} / 8^{\text {th }}$ stages III-IV) and the regression analyses were restricted in the subgroup of patients ( 468 cases) with the TNM $8^{\text {th }}$ stages I-II, both TNM $8^{\text {th }}$ (i.e. stages II vs stage I) and higher ATA risk categories (intermediate-high risk vs low risk) maintained the significant correlations with structural recurrences (Table 4). Moreover, in the TNM $8^{\text {th }}$ stages I and II, the risk of structural recurrences was higher in downstaged patients as compared to those who were not downstaged (HR 4.23, 95\% CI 1.71-10.42; $P=0.002$ ). Specifically, the risk of structural recurrence was statistically significant in patients in whom the downstaging was induced by changes in tumour classification (HR 6.18, 95\% CI 2.20-17.40; $P=0.001)$, but not in those who were downstaged due to increase in age cut-off (HR 2.80, 95\% CI 0.86-9.19; $P=0.09$ ) (Fig. 4).

\section{Discussion}

In this retrospective study, patients who were downstaged by TNM $8^{\text {th }}$ were classified more frequently as intermediatehigh ATA risk, more frequently had persistent disease, (c) 2020 Society for Endocrinology Published by Bioscientifica Ltd. Printed in Great Britain 
Table 4 Results of univariate and multivariate Cox analyses evaluating the determinants of structural recurrences.

\begin{tabular}{|c|c|c|c|}
\hline & \multicolumn{3}{|c|}{ Whole population (480 cases) } \\
\hline & \multirow[t]{2}{*}{ Univariate analysis $\mathrm{HR}(95 \% \mathrm{Cl})$} & \multicolumn{2}{|c|}{ Multivariate analysis $\mathrm{HR}(95 \% \mathrm{Cl})$} \\
\hline & & Model\#1 & Model\#2 \\
\hline Age & $1.01(0.98-1.04 ; P=0.55)$ & - & - \\
\hline Sex (males vs females) & $0.78(0.28-2.14 ; P=0.63)$ & - & - \\
\hline $\begin{array}{l}\text { ATA risk stratification (intermediate-high } \\
\text { risk vs low risk) }\end{array}$ & $2.93(1.62-5.29 ; P<0.001)$ & $2.28(1.04-4.99 ; P=0.04)$ & $2.68(1.33-5.38 ; P=0.006)$ \\
\hline TNM-7th staging system & $1.72(1.23-2.39 ; P=0.001)$ & $1.24(0.80-1.93 ; P=0.32)$ & - \\
\hline \multirow[t]{4}{*}{ TNM-8th staging system } & $2.03(1.22-3.38 ; P=0.006)$ & - & $1.17(0.62-2.19 ; P=0.62)$ \\
\hline & \multicolumn{3}{|c|}{ Patients in stages I-II by TNM-8th (468 cases) } \\
\hline & Univariate analysis $\mathrm{HR}(95 \% \mathrm{Cl})$ & \multicolumn{2}{|c|}{ Multivariate analysis $\mathrm{HR}(95 \% \mathrm{Cl})$} \\
\hline & & Model\#1 & Model\#2 \\
\hline Age & $1.00(0.97-1.04 ; P=0.74)$ & & \\
\hline Sex (males vs females) & $0.75(0.27-2.07 ; P=0.58)$ & & \\
\hline $\begin{array}{l}\text { ATA risk stratification (intermediate-high } \\
\text { risk vs low risk) }\end{array}$ & $3.42(1.76-6.64 ; P<0.001)$ & $2.41(1.08-5.38 ; P=0.03)$ & $2.70(1.32-5.52 ; P=0.006)$ \\
\hline TNM-7th (III-IV vs I-II stages) & $5.27(2.11-13.16 ; P<0.001)$ & $2.76(0.95-7.98 ; P=0.06)$ & - \\
\hline TNM-8th (II vs I stage) & $8.29(3.09-22.19 ; P<0.001)$ & & $4.82(1.69-13.72 ; P=0.003)$ \\
\hline
\end{tabular}

Model\#1: TNM-7th and ATA risk stratification; Model\#2: TNM- $8^{\text {th }}$ and ATA risk stratification.

and showed higher risk of structural recurrence when compared to patients who were in the same TNM stages but not downstaged. The risk of structural recurrence was particularly higher in patients in whom the downstaging was induced by changes in tumour classification. Interestingly, patients in the TNM $8^{\text {th }}$ stage II showed lower probability of excellent response and higher risk of structural recurrences as compared to patients with stage I.

The $8^{\text {th }}$ edition of TNM staging system brought a series of changes in the management of DTC in order to

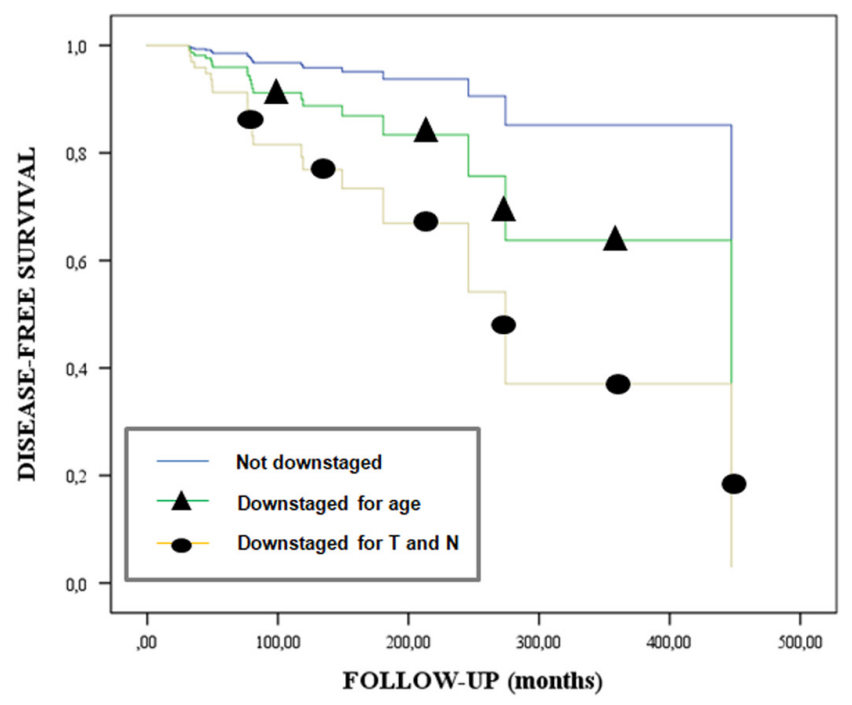

Figure 4

Disease-free survival (DFS) in patients re-classified in the TNM $8^{\text {th }}$ stages $\mathrm{I}-\mathrm{Il}$ and stratified for the downstaging. A full color version of this figure is available at https://doi.org/10.1530/ERC-19-0412.

(c) 2020 Society for Endocrinology Published by Bioscientifica Ltd. Printed in Great Britain appropriately identify patients at higher risk of diseasespecific death (Kim et al. 2017c) and classify patients into the lower stages as being at low risk of dying (Kim et al. 2017a,c). In agreement with previous studies (Pontius et al. 2017, Kim et al. 2018a, Lamartina et al. 2018, Shteinshnaider et al. 2018, Tam et al. 2018), TNM $8^{\text {th }}$ resulted in the downstaging of $28.3 \%$ of our patients. Noteworthy, similar to other experiences (Ganly et al. 2015, Kim et al. 2017b, 2018a), the restaging left only $2.5 \%$ of patients in the highest stages (III-IV), with respect to $22.7 \%$ in the previous edition. The increase in age threshold to 55 years at diagnosis, a decrease in the negative prognostic value given to lymph node metastases, and the removal of microscopic ETE from the definition of T3 disease were the variables responsible for the downstaging of DTC patients by TNM $8^{\text {th }}$ edition (Amin et al. 2017). Different from previous reports (Pontius et al. 2017), in our study there was an equilibrium between the variables responsible for the downstaging of DTC patients, making it possible to discriminate for the first time between the impact of decrease in age cut-off and that of change in tumour classification on predicting response to therapy and recurrence of disease.

The TNM staging system was designed to predict mortality but not recurrence. As a matter of fact, the risk of death in DTC patients does not effectively reflect the risk of recurrence (Tuttle et al. 2010, Vaisman et al. 2012), a much more frequent event with respect to the extremely low disease-specific mortality (i.e. only $2-4 \%$ ) (Haugen et al. 2016). For this reason, ATA guidelines proposed evaluation of the initial risk stratification subdividing 
DTC patients into low, intermediate, and high-risk categories. Our study confirmed that ATA risk stratification was the main predictor of recurrence in DTC patients as compared to TNM staging systems. Indeed, the ATA risk classification is based on several clinicopathological and molecular findings, not all of which are contemplated in the TNM staging system (Tuttle et al. 2010, Haugen et al. 2016). In our study, the application of TNM $8^{\text {th }}$ led to an increase in the number of patients classified as intermediate-high ATA risk in the lowest TNM stages. Specifically, the percentage of intermediate-high risk was higher in downstaged patients as compared to those who were not downstaged. This finding supports the working hypothesis that the downstaging of DTC patients by TNM $8^{\text {th }}$ may underestimate the risk of recurrence, consistently with the concept that ATA risk stratification is an useful tool for predicting disease recurrence (Tuttle et al. 2010, Vaisman et al. 2012, Lee et al. 2017).

The risk of recurrence in DTC patients not only correlates with the initial ATA risk stratification, but it also depends on the response to initial therapy (Tuttle et al. 2010). In fact, the ATA risk stratification system is considered as a static parameter and only the integration of ATA risk with the patient's response to therapy provides a dynamic risk assessment which may change continuously during the follow-up and accurately predict the risk of relapse of DTC (Tuttle \& Leboeuf 2008, Tuttle et al. 2010, Castagna et al. 2011, Haugen et al. 2016). Applying TNM $8^{\text {th }}$, the percentage of excellent response was higher in patients falling into stage I, whereas patients in stage II did not show significant differences as compared to the highest stages. As a matter of fact, the downstaged patients by TNM $8^{\text {th }}$ more frequently showed an incomplete response to therapy as compared to patients who were not downstaged.

Although DTC is frequently an indolent disease, the rate of relapse is up to $30 \%$ and distant metastases occur in about $10 \%$ of DTC patients during follow-up (Sampson et al. 2007, Schmidbauer et al. 2017). Recurrences affect prognosis of DTC patients with a mortality that reaches about $11 \%$ in patients with a loco-regional recurrence and incomplete response to additional treatment and up to $55 \%$ in patients with identifiable distant metastases (Sugitani et al. 2008, Haugen et al. 2016). In our study group, about $9 \%$ of patients experienced recurrence of DTC, during a median follow-up of 59 months: $54 \%$ of patients with structural recurrence and the remaining $46 \%$ of patients with biochemical recurrence. Different from previous experiences (Nam et al. 2018), in our patients, TNM $8^{\text {th }}$ did not improve the prediction of recurrence, since several patients with aggressive disease were re-classified into lower stages (Shteinshnaider et al. 2018, Verburg et al. 2018). Noteworthy, when the analyses were performed in the early-stage DTC according to the TNM $8^{\text {th }}$ edition, the risk of structural recurrences resulted to be higher in patients with stage II as compared to those in stage I. This finding suggests that the downstaging of patients with aggressive disease by the TNM $8^{\text {th }}$ occurred predominantly in the stage II. Interestingly, the risk of recurrence was higher mainly in patients whose downstaging was induced by changes in tumour classification as compared to those who were downstaged due to the increase in age cut-off. One could argue that this result may reflect the potential negative impact of microscopic ETE on the outcome of DTC (Amin et al. 2017), even though data on this issue are still a matter of controversy (Ito et al. 2006a,b, Sugitani et al. 2008, Shin et al. 2013, Santos \& Bugalho 2016, Al-Qurayshi et al. 2017, Youngwirth et al. 2017, Kim et al. 2018b, Tran et al. 2018). However, the risk of recurrence in the presence of microscopic ETE is not negligible as highlighted in the ATA guidelines in which microscopic ETE is considered a criterion for classifying patients at intermediate risk of recurrence and candidates for post-surgical radioiodine ablation (Haugen et al. 2016). Moreover, results of a metanalysis reported that microscopic ETE may have a negative impact on the prognosis of patients with papillary thyroid carcinoma, especially in patients with larger tumour size and higher presence of lymph node metastases (Yin et al. 2016). Similarly, in a recent study, microscopic ETE was considered an unfavourable prognostic factor in larger tumours without lymph node metastases at diagnosis (Castagna et al. 2018). Therefore, the negative value of microscopic ETE can explain our increased risk of recurrences in downstaged patients for tumour classification using TNM $8^{\text {th }}$ edition. These data further justify the proposal for a subcategorization of $\mathrm{T}$ categories on the basis of presence or absence of microscopic ETE in order to guide the management of DTC patients (Schmid et al. 2019). Another change in tumour classification is correlated to the decrease in the negative prognostic value given to lymph node metastases. In the latest TNM, the decrease in the unfavourable prognostic significance attributed to cervical lymph node metastases in patients $\geq 55$ years and the lack of distinction between $\mathrm{N} 1 \mathrm{a}$ and N1b were responsible for the downstaging of many patients (Edge et al. 2010, Amin et al. 2017). This has been questioned by several authors, concerned that (c) 2020 Society for Endocrinology Published by Bioscientifica Ltd. Printed in Great Britain 
TNM $8^{\text {th }}$ may underestimate disease severity in older patients (Kim et al. 2018a,c). In fact, the presence and location of metastatic lymph nodes may affect the prognosis of DTC patients and increase the risk of recurrence (Adam et al. 2015, Kim et al. 2018b). These changes can explain our increased rate of recurrence in lower stages of TNM $8^{\text {th }}$ and support the proposal to amend TNM staging system by re-evaluating lymph node involvement, in order to not underestimate relapses and mortality in this setting (Kim et al. 2018c).

Our study had some limitations; due to the small size of our sample and the lack of disease-specific mortality events, we were not able to evaluate overall survival and disease-specific survival, but we were able to evaluate disease-free survival. Another limitation is linked to the lack of information on the number and size of the removed lymph nodes, which could make the ATA risk stratification less accurate. Moreover, molecular characterization of tumours that had potential effects in the stratification of risk of recurrences was not available in our study group (Haugen et al. 2016). The retrospective design of our study did not allow to evaluate the real impact of TNM $8^{\text {th }}$ edition on the therapeutic decisionmaking in patients with DTC. Indeed, re-classification of the tumours according to TNM $8^{\text {th }}$ did not influence the treatment modalities of our patients. It is quite likely that, if the same patient cohort were collected in a prospective setting and classified primarily by TNM $8^{\text {th }}$, many patients would have received less aggressive treatment. One could argue that this approach may be cost-effective in limiting the use of potentially harmful therapies (Klein Hesselink et al. 2013, Mazziotti et al. 2018) in patients with higher overall survival. On the other hand, less aggressive treatment would eventually lead to even higher recurrence (Biondi \& Cooper 2010), with consequent increase in the clinical and therapeutic burden.

In conclusion, $\mathrm{TNM} 8^{\text {th }}$ edition did not show reliability in predicting aggressiveness of DTC and the ATA risk stratification appears to be more accurate than the TNM in predicting the recurrences of disease. Moreover, the downstaging of DTC patients, especially when performed due to changes in tumour classification, may overlook patients predisposed to structural recurrence, potentially causing uncertainty in the therapeutic decision-making at the time of disease diagnosis.

\section{Declaration of interest}

The authors declare that there is no conflict of interest that could be perceived as prejudicing the impartiality of the research reported.

\section{Funding}

This research did not receive any specific grant from any funding agency in the public, commercial, or not-for-profit sector.

\section{Author contribution statement}

M Arosio and A G A Lania are senior authors who contributed equally.

\section{Acknowledgements}

The authors would like to acknowledge Profs Furio Pacini and Paolo BeckPeccoz for their critical reading.

\section{References}

Adam MA, Pura J, Goffredo P, Dinan MA, Reed SD, Scheri RP, Hyslop T, Roman SA \& Sosa JA 2015 Presence and number of lymph mode metastases are associated with compromised survival for patients younger than age 45 years with papillary thyroid cancer. Journal of Clinical Oncology 33 2370-2375. (https://doi.org/10.1200/ JCO.2014.59.8391)

Al-Qurayshi Z, Shama MA, Randolph GW \& Kandil E 2017 Minimal extrathyroidal extension does not affect survival of welldifferentiated thyroid cancer. Endocrine-Related Cancer 24 221-226. (https://doi.org/10.1530/ERC-16-0509)

Amin MB, Greene FL, Edge SB, Compton CC, Gershenwald JE, Brookland RK, Meyer L, Gress DM, Byrd DR \& Winchester DP 2017 AJCC Cancer Staging Manual: continuing to build a bridge from a population-based to a more 'personalized' approach to cancer staging. CA: A Cancer Journal for Clinicians 67 93-99. (https://doi. org/10.3322/caac.21388)

Biondi B \& Cooper DS 2010 Benefits of thyrotropin suppression versus the risks of adverse effects in differentiated thyroid cancer. Thyroid 20 135-146. (https://doi.org/10.1089/thy.2009.0311)

Brierley JD, Gospodarowicz MK \& Wittekind C 2017 The principles of the TNM system. In The TNM Classification of Malignant Tumours, 8th ed., pp. 2-3. Oxford, UK: John Wiley \& Sons, Ltd.

Castagna MG, Maino F, Cipri C, Belardini V, Theodoropoulou A, Cevenini G \& Pacini F 2011 Delayed risk stratification, to include the response to initial treatment (surgery and radioiodine ablation), has better outcome predictivity in differentiated thyroid cancer patients. European Journal of Endocrinology 165 441-446. (https://doi. org/10.1530/EJE-11-0466)

Castagna MG, Forleo R, Maino F, Fralassi N, Barbato F, Palmitesta P, Pilli T, Capezzone M, Brilli L, Ciuoli C, et al. 2018 Small papillary thyroid carcinoma with minimal extrathyroidal extension should be managed as ATA low-risk tumor. Journal of Endocrinological Investigation 41 1029-1035. (https://doi.org/10.1007/s40618-0180854-8)

Edge SB, Byrd DR, Compton CC, Fritz AG, Greene FL \& Trotti A 2010 AJCC Cancer Staging Manual, 7th ed. New York, NY, USA: Springer.

Fiteni F, Westeel V, Pivot X, Borg C, Vernerey D \& Bonnetain F 2014 Endpoints in cancer clinical trials. Journal of Visceral Surgery $\mathbf{1 5 1}$ 17-22. (https://doi.org/10.1016/j.jviscsurg.2013.10.001)

Ganly I, Nixon IJ, Wang LY, Palmer FL, Migliacci JC, Aniss A, Sywak M, Eskander AE, Freeman JL, Campbell MJ, et al. 2015 Survival from differentiated thyroid cancer: what has age got to do with it? Thyroid 25 1106-1114. (https://doi.org/10.1089/thy.2015.0104)

Haugen BR, Alexander EK, Bible KC, Doherty GM, Mandel SJ, Nikiforov YE, Pacini F, Randolph GW, Sawka AM, Schlumberger M, et al. 20162015 American Thyroid Association management guidelines for adult patients with thyroid nodules and differentiated https://erc bioscientifica com

https://doi.org/10.1530/ERC-19-0412
(C) 2020 Society for Endocrinology Published by Bioscientifica Ltd. Printed in Great Britain 
thyroid cancer: the American Thyroid Association Guidelines Task Force on Thyroid Nodules and Differentiated Thyroid Cancer. Thyroid 26 1-133. (https://doi.org/10.1089/thy.2015.0020)

Ito Y, Tomoda C, Uruno T, Takamura Y, Miya A, Kobayashi K, Matsuzuka F, Kuma K \& Miyauchi A $2006 a$ Minimal extrathyroid extension does not affect the relapse-free survival of patients with papillary thyroid carcinoma measuring $4 \mathrm{~cm}$ or less over the age of 45 years. Surgery Today 36 12-18. (https://doi.org/10.1007/s00595-005-3090-8)

Ito Y, Tomoda C, Uruno T, Takamura Y, Miya A, Kobayashi K, Matsuzuka F, Kuma K \& Miyauchi A 2006b Prognostic significance of extrathyroid extension of papillary thyroid carcinoma: massive but not minimal extension affects the relapse-free survival. World Journal of Surgery 30 780-786. (https://doi.org/10.1007/s00268-005-0270-z)

Kim M, Kim WG, Oh HS, Park S, Kwon H, Song DE, Kim TY, Shong YK, Kim WB, Sung TY, et al. 2017a Comparison of the seventh and eighth editions of the American Joint Committee on Cancer/Union for International Cancer Control Tumor-Node-Metastasis Staging system for differentiated thyroid cancer. Thyroid 27 1149-1155. (https://doi.org/10.1089/thy.2017.0050)

Kim M, Kim YN, Kim WG, Park S, Kwon H, Jeon MJ, Ahn HS, Jung SH, Kim SW, Kim WB, et al. 2017b Optimal cut-off age in the TNM staging system of differentiated thyroid cancer: is 55 years better than 45 years? Clinical Endocrinology 86 438-443. (https://doi. org/10.1111/cen.13254)

Kim TH, Kim YN, Kim HI, Park SY, Choe JH, Kim JH, Kim JS, Oh YL, Hahn SY, Shin JH, et al. 2017c Prognostic value of the eighth edition AJCC TNM classification for differentiated thyroid carcinoma. Oral Oncology 71 81-86. (https://doi.org/10.1016/j. oraloncology.2017.06.004)

Kim M, Jeon MJ, Oh HS, Park S, Song DE, Sung TY, Kim TY, Chung KW Kim WB, Shong YK, et al. 2018a Prognostic implication of N1b classification in the eighth edition of the tumor-node-metastasis staging system of differentiated thyroid cancer. Thyroid 28 496-503. (https://doi.org/10.1089/thy.2017.0473)

Kim M, Kim HI, Jeon MJ, Kim HK, Kim EH, Yi HS, Kim ES, Kim H, Kim BH, Kim TY, et al. 2018b Eighth edition of tumor-nodemetastasis staging system improve survival predictability for papillary, but not follicular thyroid carcinoma: a multicenter cohort study. Oral Oncology 87 97-103. (https://doi.org/10.1016/j. oraloncology.2018.10.029)

Kim M, Kim HK, Kim HI, Kim EH, Jeon MJ, Yi HS, Kim ES, Kim H, Kim TH, Kim BH, et al. 2018c Modification of the eight-edition tumor-node-metastasis staging system with N1b for papillary thyroid carcinoma: a multi-institutional cohort study. Oral Oncology 86 48-52. (https://doi.org/10.1016/j.oraloncology.2018.09.008)

Klein Hesselink EN, Klein Hesselink MS, de Bock GH, Gansevoort RT, Bakker SJ, Vredeveld EJ, van der Horst-Schrivers AN, van der Horst IC, Kamphuisen PW, Plukker JT, et al. 2013 Long-term cardiovascular mortality in patients with differentiated thyroid carcinoma: an observational study. Journal of Clinical Oncology 31 4046-4053. (https://doi.org/10.1200/JCO.2013.49.1043)

Lamartina L, Grani G, Arvat E, Nervo A, Zatelli MC, Rossi R, Puxeddu E, Morelli S, Torlontano M, Massa M, et al. 2018 8th edition of the AJCC/TNM staging system of thyroid cancer: what to expect (ITCO\#2). Endocrine-Related Cancer 25 L7-L11. (https://doi. org/10.1530/ERC-17-0453)

Lee SG, Lee WK, Lee HS, Moon J, Lee CR, Kang SW, Jeong JJ, Nam KH, Chung WY, Jo YS, et al. 2017 Practical performance of the 2015 American Thyroid Association guidelines for predicting tumor recurrence in patients with papillary thyroid cancer in South Korea. Thyroid 27 174-181. (https://doi.org/10.1089/thy.2016.0252)

Mazziotti G, Formenti AM, Frara S, Olivetti R, Banfi G, Memo M, Maroldi R, Giubbini R \& Giustina A 2018 High prevalence of radiological vertebral fractures in women on thyroid-stimulating hormone-suppressive therapy for thyroid carcinoma. Journal of
Clinical Endocrinology and Metabolism 103 956-964. (https://doi. org/10.1210/jc.2017-01986)

Momesso DP \& Tuttle RM 2014 Update on differentiated thyroid cancer staging. Endocrinology and Metabolism Clinics of North America $\mathbf{4 3}$ 401-421. (https://doi.org/10.1016/j.ecl.2014.02.010)

Momesso DP, Vaisman F, Yang SP, Bulzico DA, Corbo R, Vaisman M \& Tuttle RM 2016 Dynamic risk stratification in patients with differentiated thyroid cancer treated without radioactive iodine. Journal of Clinical Endocrinology and Metabolism 101 2692-2700. (https://doi.org/10.1210/jc.2015-4290)

Nam SH, Bae MR, Roh JL, Gong G, Cho KJ, Choi SH, Nam SY \& Kim SY 2018 A comparison of the 7th and 8th editions of the AJCC staging system in terms of predicting recurrence and survival in patients with papillary thyroid carcinoma. Oral Oncology 87 158-164. (https://doi.org/10.1016/j.oraloncology.2018.11.003)

Nava CF, Zanella AB, Scheffel RS, Maia AL \& Dora JM 2019 Impact of the updated TNM staging criteria on prediction of persistent disease in a differentiated thyroid carcinoma cohort. Archives of Endocrinology and Metabolism 63 5-11. (https://doi. org/10.20945/2359-3997000000097)

Pacini F, Basolo F, Bellantone R, Boni G, Cannizzaro MA, De Palma M, Durante C, Elisei R, Fadda G, Frasoldati A, et al. 2018 Italian consensus on diagnosis and treatment of differentiated thyroid cancer: joint statements of six Italian societies. Journal of Endocrinological Investigation 41 849-876. (https://doi.org/10.1007/ s40618-018-0884-2)

Pontius LN, Oyekunle TO, Thomas SM, Stang MT, Scheri RP, Roman SA \& Sosa JA 2017 Projecting survival in papillary thyroid cancer: a comparison of the seventh and eighth editions of the American Joint Commission on Cancer/Union for International Cancer Control staging systems in two contemporary national patient cohorts. Thyroid 27 1408-1416. (https://doi.org/10.1089/ thy.2017.0306)

Sampson E, Brierley JD, Le LW, Rotstein L \& Tsang RW 2007 Clinical management and outcome of papillary and follicular (differentiated) thyroid cancer presenting with distant metastasis at diagnosis. Cancer 110 1451-1456. (https://doi.org/10.1002/cncr.22956)

Santos MJ \& Bugalho MJ 2016 Papillary thyroid carcinoma: different clinical behavior among pT3 tumors. Endocrine 53 754-760. (https:// doi.org/10.1007/s12020-016-0927-4)

Schmid KW, Synoracki S, Dralle H \& Wittekind C 2019 Proposal for an extended pTNM classification of thyroid carcinoma: commentary on deficits of the 8th edition of the TNM classification. Der Pathologe $\mathbf{4 0}$ 18-24. (https://doi.org/10.1007/s00292-018-0418-x)

Schmidbauer B, Menhart K, Hellwig D \& Grosse J 2017 Differentiated thyroid cancer-treatment: state of the art. International Journal of Molecular Sciences 18 E1292. (https://doi.org/10.3390/ ijms18061292)

Shin JH, Ha TK, Park HK, Ahn MS, Kim KH, Bae KB, Kim TH, Choi CS, Kim TK, Bae SK, et al. 2013 Implication of minimal extrathyroidal extension as a prognostic factor in papillary thyroid carcinoma. International Journal of Surgery 11 944-947. (https://doi.org/10.1016/j. ijsu.2013.06.015)

Shteinshnaider M, Muallem Kalmovich L, Koren S, Or K, Cantrell D \& Benbassat C 2018 Reassessment of differentiated thyroid cancer patients using the eighth TNM/AJCC classification system: a comparative study. Thyroid 28 201-209. (https://doi.org/10.1089/ thy.2017.0265)

Sugitani I, Fujimoto Y \& Yamamoto N 2008 Papillary thyroid carcinoma with distant metastases: survival predictors and the importance of local control. Surgery 143 35-42. (https://doi.org/10.1016/j. surg.2007.06.011)

Tam S, Boonsripitayanon M, Amit M, Fellman BM, Li Y, Busaidy NL, Cabanillas ME, Dadu R, Sherman S, Waguespack SG, et al. 2018 Survival in differentiated thyroid cancer: comparing the AJCC cancer
C) 2020 Society for Endocrinology Published by Bioscientifica Ltd. Printed in Great Britain 
Vaisman F, Momesso D, Bulzico DA, Pessoa CH, Dias F, Corbo R, Vaisman M \& Tuttle RM 2012 Spontaneous remission in thyroid cancer patients after biochemical incomplete response to initial therapy. Clinical Endocrinology 77 132-138. (https://doi. org/10.1111/j.1365-2265.2012.04342.x)

Verburg FA, Mäder U, Luster M \& Reiners C 2018 The effects of the Union for International Cancer Control/American Joint Committee on cancer tumour, node, metastasis system version 8 on staging of differentiated thyroid cancer: a comparison to version 7. Clinical Endocrinology 88 950-956. (https://doi.org/10.1111/cen.13597)

Yin DT, Yu K, Lu RQ, Li X, Xu J \& Lei M 2016 Prognostic impact of minimal extrathyroidal extension in papillary thyroid carcinoma. Medicine 95 e5794. (https://doi.org/10.1097/MD.000000000005794) Youngwirth LM, Adam MA, Scheri RP, Roman SA \& Sosa JA 2017 Extrathyroidal extension is associated with compromised survival in patients with thyroid cancer. Thyroid 27 626-631. (https://doi. org/10.1089/thy.2016.0132)

Received in final form 20 March 2020

Accepted 31 March 2020

Accepted Manuscript published online 31 March 2020 (c) 2020 Society for Endocrinology Published by Bioscientifica Ltd. Printed in Great Britain 